\title{
Stress-strain behaviour of pre-stressed slabs of off-shuttering formation reinforced by carbon fiber
}

\author{
Denis Panfilov, ${ }^{1, *}$, Alexander Pischulev ${ }^{1}$, and Yuriy Zhiltsov ${ }^{1}$ \\ ${ }^{1}$ Samara State Technical University, Academy of Architecture and Civil Engineering, \\ Molodogvardeyskaya St., 194, Samara, 443001, Russia
}

\begin{abstract}
The paper presents calculations result of an assembled reinforced concrete hollow core slab of off-shuttering formation which has been reinforced with pre-stressed wire in its top and bottom areas reinforced with carbon fiber, in their turn. The research also examines the existing practice of using carbon fiber as reinforcement elements of reinforced concrete structures, existing specification documents regulating carbon fiber application of carbon in the Russian Federation as well as specification documents containing information about carbon fiber strength and stress-strain properties. The article contains the information on the scheme of loading, conditions of the slab fastening, geometrical characteristics of floor slab panels, physical characteristics of concrete and reinforcement of the experimental sample; technical characteristics of carbon reinforcement elements. The research results are represented as graphs of variance of construction deflections under loading in operating conditions of a slab wIth and without cracks before its reinforcement, and also in the moment of reinforcement. The research shows that using of carbon fiber to reinforce flexural elements with preliminary stress allows to increase rigidity and crack resistance of reinforced concrete elements.
\end{abstract}

\section{Introduction}

Assembled pre-stressed hollow-core slabs of off-shuttering formation (SSF) are widely used in building construction. The reasons for that lie in their advantage in manufacturing technology; in the possibility of covering comparatively big spans (up to $12 \mathrm{~m}$ ); in economic use of materials and in the possibility of architectural re-planning of apartments. Their main peculiarity is the absence of crosswise reinforcement in vertical ribs, as well as the increased hardness due to use of pre-stressed steel reinforcement both in the low and in the top zones.

At the moment there are no specification documents in Russia regulating issues of design and calculation of slabs of off-shuttering formation. EN 1168-2012 [1] gives some recommendations of such slabs design. It is somehow not possible to use formula given in these recommendations as we didn't manage to find coherent coefficients there. Besides, the

* Corresponding author: panda-w800i@yandex.ru 
suggested methodology differs greatly from methodologies used by Russian standards. It is recommended to calculate these structures using SP 63.13330.2012 [2]. But since this regulation does not include requirements for calculation of such specific constructions as hollow core slabs, it also raises a number of questions concerning both modeling these products and peculiarities of their work at all stages of their life cycle, especially their service limit state. Calculation of structures with reinforcement elements from carbon fiber is done according to the actual SP (=Regulations) 164.1325800.2014 [3].

\section{Materials and methods}

The study continues previous researches [6-8] and examines a pre-stressed slab of offshuttering formation, its deflections, and also its work after reinforcement.

For theoretical calculations we took a slab with $220 \mathrm{~mm}$ section height, $3580 \mathrm{~mm}$ length, $1500 \mathrm{~mm}$ width. The section of the slab and its reinforcement are shown in Figure 1. The test slab PB 36.15-8Bp1400-25 characteristics are given in Table 1.

Table 1. The test slab PB 36.15-8Bp1400-25 characteristics

\begin{tabular}{|c|c|c|c|c|}
\hline Characteristic & $\begin{array}{c}\text { Design } \\
\text { value, } \mathrm{mm}\end{array}$ & $\begin{array}{c}\text { Actual value, } \\
\mathrm{mm}\end{array}$ & $\begin{array}{c}\text { Deflection, } \\
\mathrm{mm}\end{array}$ & $\begin{array}{c}\text { Limit deviation } \\
\text { according to } \\
\text { GOST 9561-2016 } \\
\text { [5], mm }\end{array}$ \\
\hline Length & 3580 & $3389 \ldots 3392$ & $+9 \ldots+12$ & \pm 12 \\
\hline Width & 1495 & $1490 \ldots 1496$ & $-5 \ldots+1$ & \pm 6 \\
\hline Cross-sectional height & 220 & $218 \ldots 221$ & $-2 \ldots+1$ & \pm 5 \\
\hline Holes width & 81 & $73 \ldots 82$ & $-9 \ldots \pm 0$ & \pm 10 \\
\hline $\begin{array}{c}\text { Thickness of concrete } \\
\text { protective layer for } \\
\text { bottom reinforcement }\end{array}$ & 20 & $17 \ldots 23$ & $-3 \ldots+3$ & \pm 5 \\
\hline $\begin{array}{c}\text { Thickness of concrete } \\
\text { protective layer for top } \\
\text { reinforcement }\end{array}$ & 20 & $27 \ldots 34$ & $+7 \ldots+14$ & \pm 5 \\
\hline
\end{tabular}

Design characteristics of the product: Calculated span of the slab: $\mathrm{Lp}=3380 \mathrm{~mm}$; plan area: $5.35 \mathrm{~m}^{2}$; concrete consumption: $0.71 \mathrm{~m}^{3}$; weight of a unit load $-1770 \mathrm{~kg}$.; concrete class: B45. Reinforcement according to the drawings of 142/15 Album 39: Top row: $2 \varnothing 5$ Bp 1400 according to GOST 7348-81 [4], has the following strength and deformation characteristics: $\mathrm{R}_{\mathrm{sn}}=1400 \mathrm{MPa} ; \mathrm{E}_{\mathrm{s}}=2 \times 105 \mathrm{MPa}$; Bottom row: 8 Ø $5 \mathrm{Bp} 1400$. Initial prestress in the reinforcement before concreting: $500 \mathrm{MPa}$ in the upper zone; $1100 \mathrm{MPa}$ in the lower zone. Stress in the reinforcement: $400 \mathrm{MPa}$ in the upper zone; $810 \mathrm{MPa}$ in the lower zone. 


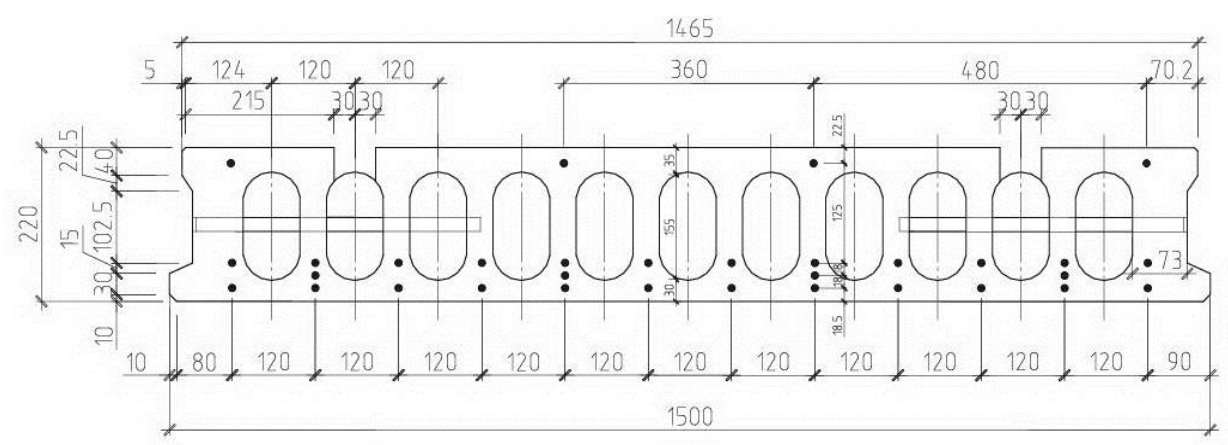

Fig. 1. Cross section of the slab and its reinforcement.

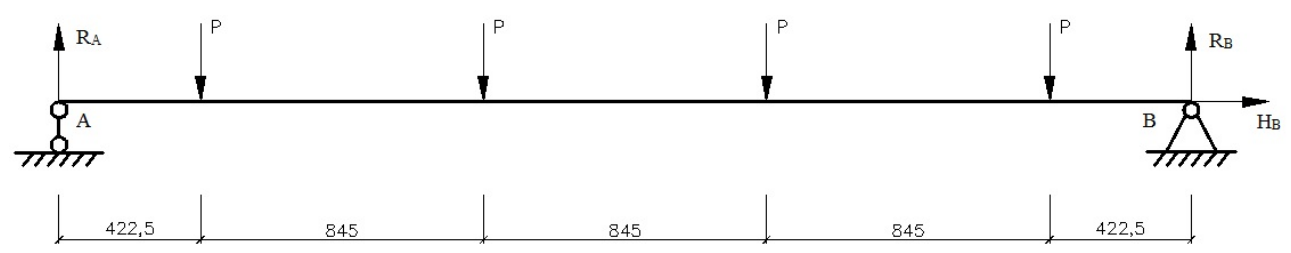

Fig. 2. Calculation model of the construction.

\section{Results}

The calculation scheme of the test of bent reinforced concrete hollow slab is accepted as a statically definable hinge-supported single-span beam loaded with four concentrated forces applied at a distance, as shown in Figure 2. Pilot installation for testing the sample shown in Figure 3. Loading of the structure was done in a stepwise fashion. The choice of control points is based on the terms of logging. Each stage does not exceed $10 \%$ of the reference load when checking strength and deformation. Figure 4 shows the photographs of the specimen prepared for the test and the pilot installation itself.

After reaching the limit force of $169.1 \mathrm{kN}$ and the formation of a crack in the middle of the span, the load drops to $119.54 \mathrm{kN}$ and a plastic centroid is formed. At this moment the construction is unloaded and the slab is reinforced with two tapes of carbon fiber FibArm Tape-230/300, with width of $300 \mathrm{~mm}$ for the entire length of the slab. The carbon fiber technical specifications are given in Table 2. 
Table 2. The carbon fiber technical specifications

\begin{tabular}{|c|c|c|}
\hline Name & $\begin{array}{c}\text { Unit of } \\
\text { measurement }\end{array}$ & Quantity \\
\hline Fiber direction & $\circ$ & 0 \\
\hline Thickness & $\mathrm{mm}$ & 0.13 \\
\hline Surface density & $\mathrm{g} / \mathrm{m}^{2}$ & $230 \pm 10$ \\
\hline Support fiber type & & Carbon fiber $12 \mathrm{~K}$ \\
\hline Tension breaking strength & $\mathrm{hPa}$ & 4.9 \\
\hline Tensile modulus & $\mathrm{hPa}$ & 245 \\
\hline Breaking elongation & $\%$ & 1.8 \\
\hline
\end{tabular}

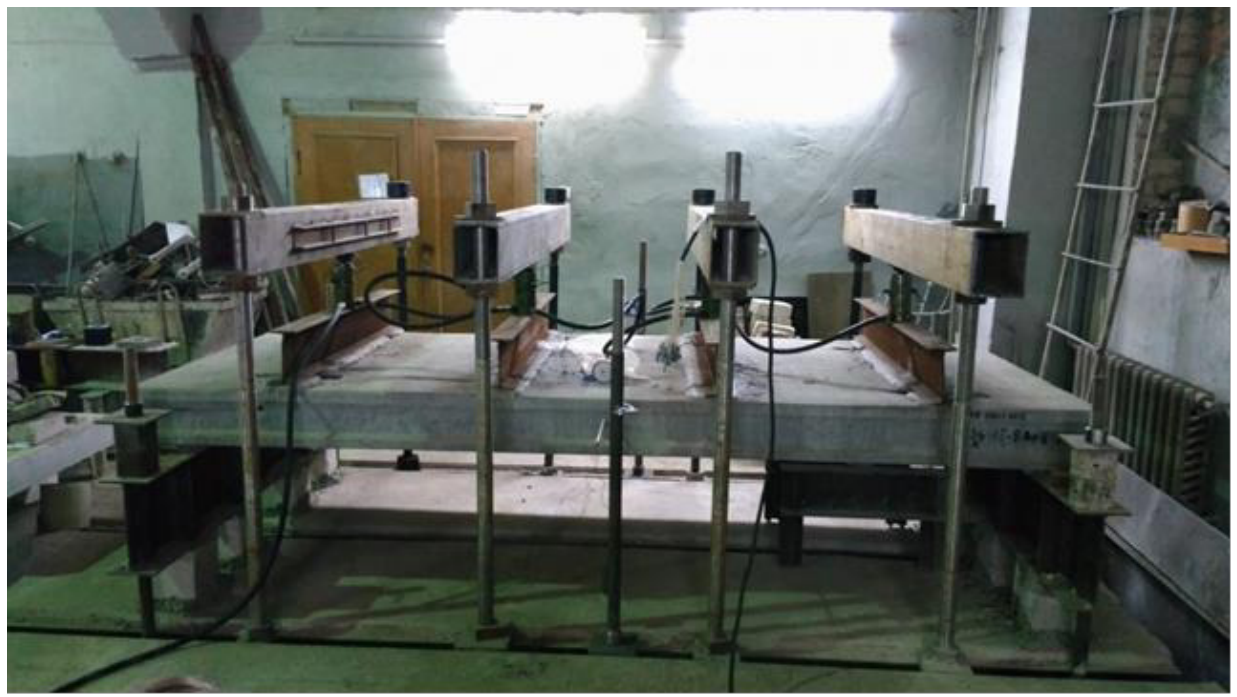

Fig. 3. Pilot installation for testing the sample. 


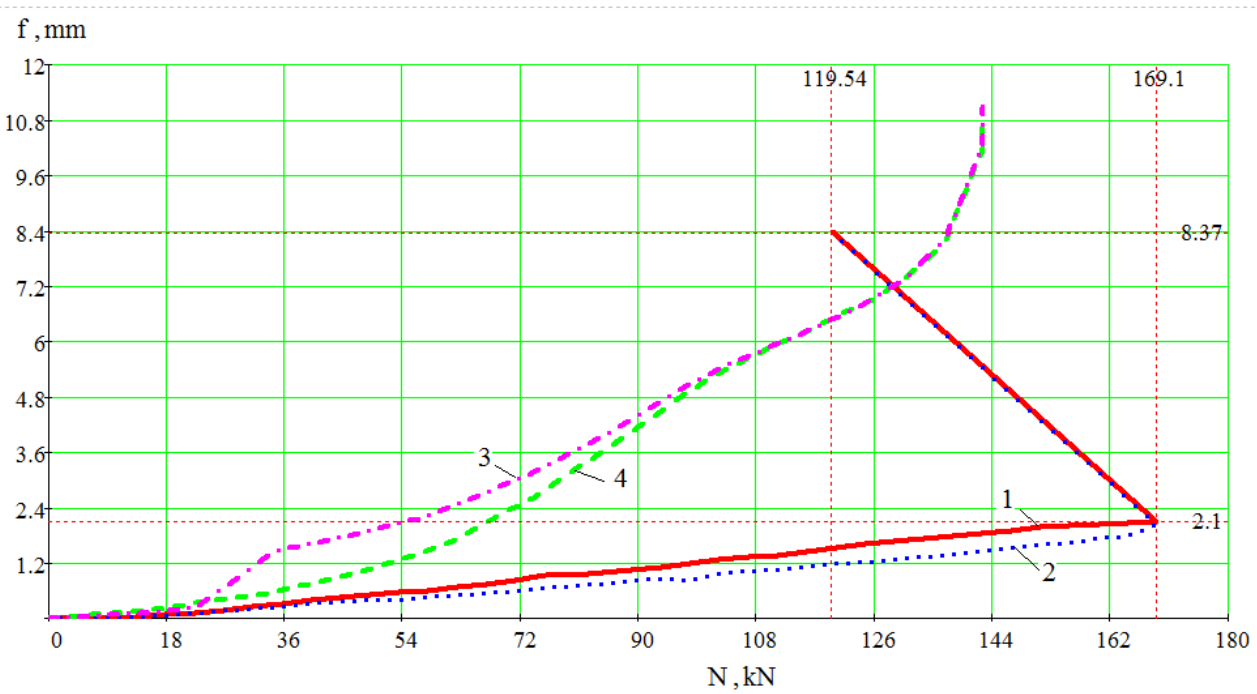

Fig. 4. Graphs of dependence of deflection value from the load degree: 1, 2 - values for the slab without reinforcement; 3,4 -values for the plate, reinforced with carbon fiber.

\section{Conclusion}

The maximum load before cracking was $169.1 \mathrm{kN}$. After the load reduction up to $119.54 \mathrm{kN}$, due to cracking, the formation of a plastic centroid took place.

The destruction of the slab with reinforcement elements took place simultaneously with the achievement of the limit tension value in the reinforcement and in concrete of the compressed zone, and with the rupture of pre-stressed reinforcement and carbon fiber.

After unloading and adding reinforcement elements, the limit load at destruction was $142.5 \mathrm{kN}$, which is significantly higher than the load at the formation of the plastic centroid, which proves the effective inclusion of the reinforcement elements in the work of the construction.

\section{References}

1. STB EN 1168-2012. Reinforced assembled units. Hollow core slabs (2012)

2. SP 63.13330.2012. Concrete and reinforced concrete structures Fundamental principles (2012)

3. SP 164.1325800.2014 Reinforcing of reinforced concrete structures with composite materials. Design Rules (2014)

4. GOST 7348-81. Carbon steel wire for reinforcement of pre-stressed reinforced concrete structures. Technical Specifications (1981)

5. GOST 9561-2016 Floor slab panels of reinforced concrete hollow slabs for buildings and structures. Technical Specifications (2016)

6. D. Panfilov, I. Piskareva, Ju. Fomina. MATEC Web of Conf., 86, 01008 (2016)

7. D.A. Panfilov, A.A. Pishchulev, Yu.V. Zhiltsov. MATEC Web of Conf., 117, 00132 (2017)

8. D.A. Panfilov, A.A. Pischulev. Procedia Engineering. 111, 626-631 (2015). 